\title{
Frequency of Medium-Chain Acyl-CoA Dehydrogenase Deficiency G-985 Mutation in Sudden Infant Death Syndrome
}

\author{
MARVIN E. MILLER, JOHN G. BROOKS, NICHOLAS FORBES, AND RICHARD INSEL
}

Department of Pediatrics, University of Rochester School of Medicine and Dentistry, Rochester, New York 14642 [M.E.M., J.G.B., R.I.], and Monroe County Medical Examiner's Office, Rochester, New York 14620 [N.F.]

\begin{abstract}
A small percentage of apparent sudden infant death syndrome (SIDS) victims may have an unsuspected metabolic disorder. Medium-chain acyl-CoA dehydrogenase (MCAD) deficiency is a disorder of fatty acid oxidation that has been the most common such metabolic disorder found in series of SIDS victims. A single mutation in MCAD deficiency has been recently described (G-985) that accounts for approximately $90 \%$ of MCAD deficiency mutations. We studied the hypothesis that heterozygosity or homozygosity for this specific MCAD deficiency mutation might be associated with SIDS. DNA was extracted from the paraffin-embedded autopsy tissues of 67 victims of SIDS in Monroe County, NY who died between 1984 and 1989. Using the polymerase chain reaction/ Ncol digestion method, we found no G-985 homozygotes and three (4.5\%) G-985 heterozygotes. In 70 newborn controls, there were no G-985 homozygotes and one (1.4\%) heterozygote. Although the frequency of G-985 heterozygotes was slightly greater than in our control group, it was not statistically different. We conclude that the specific MCAD deficiency mutation G-985 is not strongly associated with SIDS and that MCAD deficiency probably does not make a significant contribution to the etiology of SIDS. (Pediatr Res 31: 305-307, 1992)
\end{abstract}

\section{Abbreviations}

MCAD, medium-chain acyl-CoA dehydrogenase G-985, A to $G$ mutation in MCAD gene at position 985 PCR, polymerase chain reaction SIDS, sudden infant death syndrome

A small percentage of infants who die with apparent SIDS may have an unsuspected inborn error of metabolism (1). A retrospective study of 200 infants in England who unexpectedly died showed that $14(7 \%)$ had microscopic evidence of fatty changes in various tissues, suggesting a disorder of fatty acid oxidation (2). Enzyme analysis of tissues in nine of these 14 cases showed three cases of MCAD deficiency and one case of longchain acyl-CoA dehydrogenase deficiency. This observation and similar observations by others have suggested that fatty acid oxidation defects should be considered in any infant that dies with SIDS or in any baby or child who has an unexpected death $(3,4)$. There is controversy, however, as to whether fatty acid oxidation defects are present in increased frequency in SIDS (5).

Received for rapid publication December 26, 1991; accepted January 6, 1992. Correspondence: Dr. Marvin Miller, University of Rochester School of Medicine and Dentistry, Department of Pediatrics, Box 777, Rochester, NY 14642.

Supported in part by The Strong Children's Research Center.
MCAD deficiency is the most common enzyme deficiency in fatty acid oxidation (6). Affected children usually present within the first $2 \mathrm{y}$ of life with recurrent episodes of hypoglycemia that are brought on by poor nutritional intake often associated with a respiratory or gastrointestinal viral infection. Affected children often present in a coma or with an altered level of consciousness. The striking laboratory abnormality is that despite the hypoglycemia these children have a trace of or no ketone bodies in their urine. The inability to make ketone bodies reflects their inability to metabolize medium-chain fatty acids. Approximately $25 \%$ of affected children die during their initial presentation (6). Between episodes of illness, the children are clinically normal and healthy. MCAD deficiency is an autosomal recessive disorder, so there is sometimes an affected sibling.

The molecular basis of MCAD deficiency mutations was recently described by Matsubara et al. (7) and Yokota et al. (8). Each showed that there was one prevalent mutation in documented cases of MCAD deficiency, an A to G mutation at position 985 causing a lysine to glutamate substitution in the mature protein. Matsubara et al. found 31 of 34 (91\%) MCAD deficiency alleles to be G-985 and Yokota et al. found 18 of 18 $(100 \%)$ alleles to be G-985 $(7,8)$. In a larger series, Gregersen et al. (9) showed that 95 of $112(85 \%)$ MCAD deficiency alleles were G-985. The G-985 MCAD deficiency mutation can be distinguished from the wild-type allele by a PCR that uses primers that create an $N c o$ I restriction site in the mutant allele but not in the wild-type allele (8). Thus, PCR amplification of genomic DNA from tissues followed by $N c o l$ digestion and electrophoresis can readily distinguish between the G-985 mutant allele and the wild-type allele.

The characterization of one common MCAD deficiency mutation (7-9) and the ability to determine its presence in postmortem tissue by PCR (10) has prompted investigators to determine the presence of this mutation in SIDS. In at least one family, siblings who died sudden, unexpected deaths have now been retrospectively identified to have had MCAD deficiency, based on finding G-985 homozygosity in their postmortem tissue (11). The purpose of the present study was to determine the frequency of the G-985 MCAD deficiency mutation (both the heterozygous and homozygous states) in a cohort of SIDS victims and compare this frequency with that found in a control group.

\section{MATERIALS AND METHODS}

Ascertainment of SIDS cases and control cases. SIDS cases that occurred between 1984 and 1989 in Monroe County, NY had paraffin-embedded tissue available for preparation of DNA from the medical examiner's office. Each was reviewed by a pathologist and a pediatrician and met the criteria for SIDS (12). Of the 67 SIDS victims, 33 were male and 34 female, and 35 were black and 25 nonblack (seven cases did not have the race listed). The mean age of death was $3.2 \mathrm{mo}$ (SD $2.6 \mathrm{mo}$ ). 
A control group was randomly selected from infants born during 1991 in New York State who had blood spots made on filter paper for newborn screening that had not been used and were still available.

Preparation of DNA and PCR amplification. DNA was prepared from the paraffin blocks by cutting a slice of the paraffin block with a razor blade and then mincing the slice into small pieces. The paraffin was extracted twice by adding $1 \mathrm{~mL}$ of xylene and mixing for $30 \mathrm{~min}$, pelleting the tissue by centrifugation for $3 \mathrm{~min}$, and aspirating the supernatant. The pelleted tissue was washed with $800 \mu \mathrm{L}$ of ethanol, dried in a speed vacuum, and then digested in $800 \mu \mathrm{L}$ of digestion buffer [ $50 \mathrm{mM}$ Tris (pH 8.5), 1 mM EDTA, and $0.5 \%$ Tween 20] and $50 \mu \mathrm{g}$ of proteinase $\mathrm{K}$ overnight at $37^{\circ} \mathrm{C}$. The proteinase $\mathrm{K}$ was then heat inactivated at $95^{\circ} \mathrm{C}$ for $10 \mathrm{~min}$. The sample was centrifuged, and the supernatant was used as a DNA source for PCR amplification.

The primers and PCR conditions used were those described by Yokota et al. (8). The sequence of the $5^{\prime}$ primer was $5^{\prime}$ ATATCATTTATGCTGGCTGAAATGGCCATG and that of the $3^{\prime}$ primer was 5'-GAACCCCTCCAACTAAGACCA. The PCR consisted of $80 \mu \mathrm{L}$ of water, $8 \mu \mathrm{L}$ of nucleotides, $10 \mu \mathrm{L}$ of $10 \times$ PCR buffer, $5 \mu \mathrm{L}$ of the $5^{\prime}$ primer, $5 \mu \mathrm{L}$ of the $3^{\prime}$ primer, $1 \mu \mathrm{L}$ of the DNA-containing supernatant, and $1 \mu \mathrm{L}$ of Taq polymerase. Initial denaturation was performed at $94^{\circ} \mathrm{C}$ for 7 min followed by 35 cycles of amplification with each cycle, consisting of $1 \mathrm{~min}$ of denaturation of $94^{\circ} \mathrm{C}, 2 \mathrm{~min}$ of annealing at $55^{\circ} \mathrm{C}$, and $3 \mathrm{~min}$ of extension at $72^{\circ} \mathrm{C}$. There was a final extension at $72^{\circ} \mathrm{C}$ for $7 \mathrm{~min}$.

DNA was prepared from the dried blood spots of newborns by placing the blood-spotted filter paper in $80 \mu \mathrm{L}$ of $1 \times$ PCR buffer at room temperature for $1 \mathrm{~h}$ and then at $100^{\circ} \mathrm{C}$ for 10 min. The PCR was then performed in the same tube with the filter paper spot still present using the same reaction mixture and PCR conditions as described above.

NcoI digestion. $N$ coI digestion of the amplified product was performed with $13 \mu \mathrm{L}$ of the PCR product, $1.5 \mu \mathrm{L}$ of $10 \times$ digestion buffer, and $0.5 \mu \mathrm{L}$ of $N c o$ I endonuclease $(8 \mathrm{U} / \mu \mathrm{L})$ at $37^{\circ} \mathrm{C}$ overnight. Both the $15 \mu \mathrm{L}$ of digested product and $15 \mu \mathrm{L}$ of undigested PCR product were electrophoresed on 3\% NuSieve (FMC Bioproducts, Rockland, ME) $/ 1 \%$ agarose gel with ethidium bromide at $100 \mathrm{~V}$ for $90 \mathrm{~min}$.

\section{RESULTS}

The PCR product from the wild-type allele gives a single, uncut, 87-bp fragment in both the undigested and NcoI-digested samples (Fig. 1). The PCR product from the G-985 allele gives a single, 87-bp fragment in the undigested sample, but gives two bands of 61 and $26 \mathrm{bp}$ in the $N c o$ I-digested sample. Figure 1 is a gel showing a SIDS victim that was homozygous for the normal MCAD allele and a SIDS victim that was heterozygous for G985.

The G-985 mutation was found in the heterozygous state in three of 67 SIDS cases (4.5\%) and in one of 70 control cases $(1.4 \%)$, a difference that was not statistically significant. There were no G-985 homozygotes in either the SIDS group or the control group. Because there was no evidence of fatty infiltration of tissues in any of the SIDS cases and because the G-985 mutation composes almost $90 \%$ of all MCAD deficiency mutations, it is presumed that the three SIDS victims with the G-985 mutation had a wild-type allele for their other allele, and thus were not compound heterozygotes for MCAD deficiency.

Of the three SIDS victims who were G-985 heterozygotes, one was a black female who died at 2 mo of age, one was a black male who died at 2.5 mo of age, and one was a Caucasian female who died at 20 mo of age.
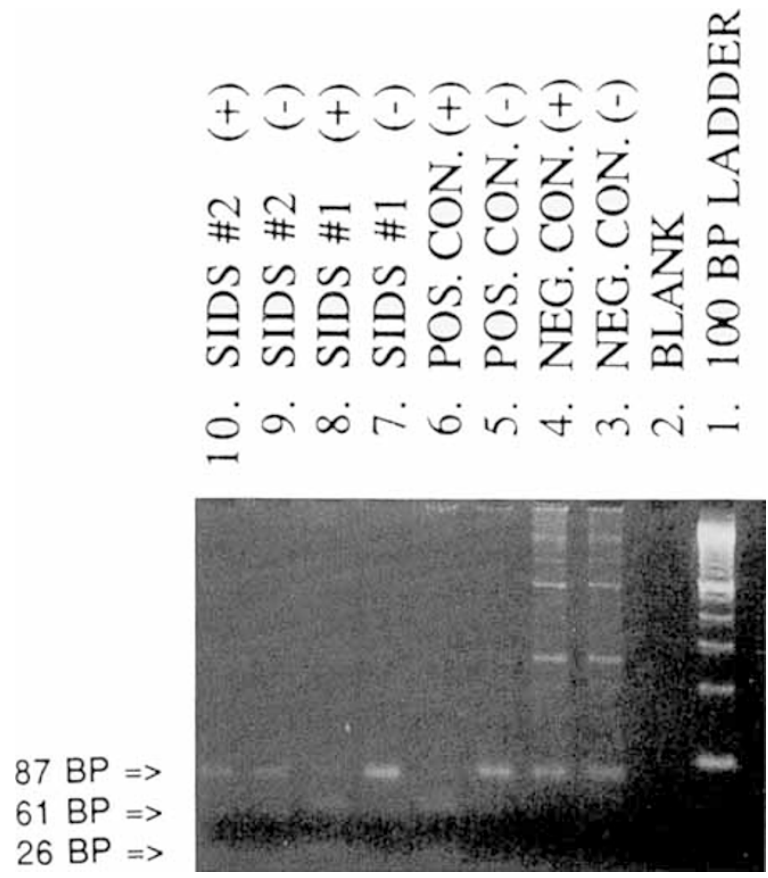

Fig. 1. A $3 \%$ NuSieve $/ 1 \%$ agarose gel was used to determine the presence of G-985 MCAD deficiency mutation. PCR products were loaded in the origin of each lane and run for $90 \mathrm{~min}$ at $100 \mathrm{~V}$. Each control and sample was run with $(+)$ and without $(-) N c o$ I restriction enzyme digestion overnight at $37^{\circ} \mathrm{C}$ before electrophoresis. Lane $I$ is the 100-bp ladder. Lane 2 is the PCR blank. Lanes 3 and 4 are the negative control from genomic DNA in a person who is homozygous normal for MCAD. The size of the uncut PCR product with the primers used was $87 \mathrm{bp}$. Because neither allele has G-985, there was no cutting of the PCR product with $\mathrm{Ncol}$. Lanes 5 and 6 are the positive control from genomic DNA from a cell line that is homozygous for G-985 (GM 4488 from Human Genetic Mutant Cell Repository, Institute for Medical Research, Camden, NJ). Because both alleles have G-985, each is cut by $N c o I$ to give fragments that are 61 and 26 bp long. The 87 -bp fragment can be seen in lane 5, and the 61- and 26-bp fragments can be seen in lane 6 (at the top and bottom of the dye front) after $\mathrm{Ncol}$ digestion. Lanes 7 and 8 are from DNA extracted from the paraffin blocks of SIDS victim 1, who was heterozygous for G-985 as evidenced by the presence of the 87-, 61-, and 26- bp fragments in lane 8. Lanes 9 and 10 are from DNA extracted from the paraffin blocks of SIDS victim 2, who was homozygous normal for MCAD as evidenced by the lack of $N$ col cutting in lane 10 .

\section{DISCUSSION}

These results indicate that in this population of SIDS victims there were no cases of G-985 MCAD deficiency homozygotes and probably no cases of G-985 compound heterozygotes. The finding of a $4.5 \%$ frequency of G-985 heterozygotes in the SIDS population is somewhat higher than that in our control group and in other control populations studied. Using filter paper blood spots from newborns, Matsubara et al. (13) found a G-985 heterozygote frequency of $2.5 \%$ in Birmingham, England, $1.5 \%$ in Melbourne, $0.9 \%$ in Houston, and $0 \%$ in Sendai, Japan.

At least three other recent studies have described in preliminary form the frequency of G-985 in SIDS (14-16). The results of these studies are summarized in Table 1 . The combined findings show that there were no cases of G-985 homozygotes and seven $(1.8 \%)$ cases of G-985 heterozygotes out of 379 cases of SIDS. Clearly, homozygous G-985 MCAD deficiency is not a major contributor to SIDS. The present study and study by Chen et al. (14) found a slightly greater heterozygote frequency in the SIDS group compared with the control group. In our study, the difference was not statistically different, and in Chen's study, the results approach statistical significance. This observation will 
Table 1. Frequency of G-985 MCAD deficiency mutation in SIDS and control populations

\begin{tabular}{|c|c|c|c|}
\hline Study and population & $(n)$ & $\begin{array}{c}\text { G-985 } \\
\text { homozygotes }\end{array}$ & $\begin{array}{c}\text { G-985 heter- } \\
\text { ozygotes }\end{array}$ \\
\hline \multicolumn{4}{|l|}{ Present } \\
\hline SIDS (Monroe County, NY) & 67 & 0 & $3(4.5)^{*}$ \\
\hline Control-newborns, (NY) & 70 & 0 & $1(1.4)^{*}$ \\
\hline \multicolumn{4}{|l|}{ Chen et al. (14) } \\
\hline SIDS (North Carolina) & 119 & 0 & $4(3.4) \dagger$ \\
\hline Control (North Carolina) & 2611 & 0 & $31(1.2) \dagger$ \\
\hline \multicolumn{4}{|l|}{ Deufel et al. (15) } \\
\hline SIDS (Germany) & 153 & 0 & $0(0) \ddagger$ \\
\hline Control (Germany) & 200 & 0 & $14(7.0) \ddagger$ \\
\hline \multicolumn{4}{|l|}{ Chinsky et al. (16) } \\
\hline SIDS (Maryland) & 40 & 0 & $0(0)$ \\
\hline \multicolumn{4}{|l|}{ Control-none given } \\
\hline \multicolumn{4}{|l|}{ Total } \\
\hline SIDS & 379 & 0 & $7(1.8) \S$ \\
\hline Control & 2881 & 0 & $46(1.6) \S$ \\
\hline
\end{tabular}

*, Not significantly different by Fisher's exact test $(p=0.24)$.

$\dagger$, Significantly different by $\chi^{2}$ test (excess G-985) $(p=0.03)$.

$\ddagger$, Significantly different by $\chi^{2}$ test (deficient G-985) $(p<0.001$ ).

$\S$. Not significantly different by $\chi^{2}$ test.

need to be clarified with larger studies. However, these differences are small and would suggest that G-985 heterozygosity is not strongly associated with SIDS. Deufel et al. (15) found no G-985 heterozygotes in 153 cases of SIDS in Germany, which was significantly different from the G-985 heterozygote frequency in the control group. When the combined totals of all four studies are analyzed, there is no statistical difference between the observed number of G- 985 heterozygotes and the expected number.

The sample size of our SIDS group is small, and the ethnic and racial makeup of Monroe County, NY may be different from that in other parts of the world. For these reasons, the frequency of G-985 MCAD deficiency needs to be studied in a much larger SIDS population that looks at the race and ethnicity of the SIDS victim as well as the frequency of G-985 MCAD deficiency in control populations that are stratified by race and ethnicity. It is noteworthy that two of the three SIDS victims in our study who were G-985 heterozygotes were black and the frequency of G-985 MCAD deficiency appears to be lower in blacks than in Caucasians (9).

Previous pathologic studies of series of SIDS victims have shown an increased frequency of fatty acid oxidation defects, specifically MCAD deficiency. One reason for the discrepancy in the frequency of MCAD deficiency in these pathologic/biochemical studies compared with the frequency of MCAD deficiency in SIDS obtained through molecular genetic approaches to determine the G-985 MCAD deficiency mutation is the strictness with which the diagnosis of SIDS was made. SIDS is defined as "the sudden death of any infant or young child which is unexpected by history, and in which a thorough postmortem examination fails to demonstrate an adequate cause of death" (12). If the strict definition of SIDS were used, a pathologist would not sign out a case of sudden, unexpected death in a 1- to 12-mo-old baby if there was significant fatty infiltration of the liver. Rather, this victim might be suspected of having a fatty acid oxidation defect and appropriately worked up. If, however, there was significant fatty infiltration of the liver and this was not recognized as being a fatty acid oxidation defect, this case might be signed out as SIDS.

The history preceding a SIDS death and that preceding the onset of symptoms in MCAD deficiency are distinctly different. SIDS deaths are not preceded by any signs of significant illness. Classically, the baby is put to sleep and then found dead in bed without ever even having struggled or cried. There is usually no history of poor eating. MCAD deficiency, however, characteristically presents with vomiting, lethargy, and hypoglycemia that are provoked by fasting (6). Thus, the very different clinical pictures of these two disorders would suggest that SIDS is probably not caused by MCAD deficiency. Moreover, if a thorough autopsy examination were performed in a case of suspected SIDS, the finding of a normal liver without fatty infiltration would be strong evidence that the baby did not have MCAD deficiency.

These observations suggest that MCAD deficiency is not a major cause of SIDS. However, there may be a very small subset of SIDS victims that is related to MCAD deficiency. There are two situations in unexpected childhood death in which MCAD deficiency should be considered and further evaluated by biochemical and molecular testing. The first is when there are sibship occurrences of SIDS, and the second is when significant fatty infiltration of the liver is found at autopsy of a presumed SIDS victim. The present evidence from our study and others strongly suggests that MCAD deficiency or heterozygosity for MCAD deficiency is not a major contributor to SIDS. Larger studies of SIDS victims that are stratified by race and ethnic group need to be done to confirm these preliminary findings.

Acknowledgment. The authors thank Dr. Ken Pass of the New York State Newborn Screening Program for providing the newborn-screening filter paper blood spots.

\section{REFERENCES}

1. Emery JL, Variend S, Howat AJ, Vawter GF 1988 Investigation of inborn errors of metabolism in unexpected infant deaths. Lancet 2:29-31

2. Howat AJ, Bennett MJ, Variend S, Shaw L, Engel PC 1985 Defects of metabolism of fatty acids in the sudden infant death syndrome. Br Med J 290:1771-1773

3. Harpey JP, Charpentier C, Paturneau-Jouas M 1990 Sudden infant death syndrome and inherited disorders of fatty acid $\beta$-oxidation. Biol Neonate 58(suppl 1):70-80

4. Rebuffat E, Sottiaux M, Goyens P, Blum D, Vamos E, Van Vliet G, Hasaerts $D$, Steenhout P, Demeirler L, Kahn A 1991 Sudden infant death syndrome, as first expression of a metabolic disorder. In: Schaub $J$, Van Hoof $F$, Vis HL (eds) Inborn Errors of Metabolism, Nestle Nutrition Workshop Series, Vol 24. Raven Press. New York, pp 71-78

5. Holton JB, Allen JT, Green CA, Partington S, Gilbert RE, Berry PJ 1991 Inherited metabolic diseases in the sudden infant death syndrome. Arch Dis Child 66:1315-1317

6. Roe CR, Coates PM 1989 Acyl-CoA dehydrogenase deficiencies. In: Scriver SR, Beaudet AL, Sly WS, Valle D (eds) The Metabolic Basis of Inherited Disease, 6th Ed. McGraw-Hill, New York, pp 889-914

7. Matsubara Y, Narisawa K, Miyabayashi S, Tada K, Coates PM, Bachmann C, Elsas LJ, Pollitt RJ, Rhead WJ, Roe CR 1990 Identification of a common mutation in patients with MCAD deficiency. Biochem Biophys Res Commun 171:498-505

8. Yokota I, Indo Y, Coates P, Tanaka K 1990 Molecular basis of MCAD deficiency. J Clin Invest 86:1000-1003

9. Gregersen W, Winter V, Kolvraa S, Andresen B, Bross P, Blakemore A, Curtis D, Bolund L 1991 Molecular analysis of MCAD deficiency in Europe. Am J Hum Genet 49 (suppl):39(abstr)

10. Wright K, Manos M 1990 Sample preparation from paraffin-embedded tissues. In: Innis MA, Gelfand DH, Sninsky JJ, White TJ (eds) PCR Protocols. Academic Press, New York, pp 153-158

11. Ding JH, Roe CR, Iafolla AK, Chen YT 1991 MCAD deficiency and sudden infant death. N Engl J Med 325:61-62

12. Bergman A, Beckwith JB, Ray CG 1970 Proceedings of the Second International Conference on Causes of Sudden Death in Infants. University of Washington Press, Seattle, p 18

13. Matsubara Y, Narisawa K, Tada K, Ikeda H. Ye-Qi Y, Danks D, Green A, McCabe E 1991 Prevalence of K329E mutation in MCAD gene determined from Guthrie cards. Lancet 338:552-553

14. Chen YT, Millington DS, Zhang W, Ding JH, Terada N, Iafollo AK, Kahler SG, Roe CR 1991 Workshop and Abstracts from the Second International Symposium on Clinical, Biochemical, and Molecular Aspects of Fatty Acid Oxidation Defects. Philadelphia, abstr W-7

15. Deufel T, Mack M, Muller B, Wiske J, Findeisen-Huls M, Bajanowski T, Jorch G, Brinkman B, Gregersen N, Roscher AA 1991 Workshop and Abstracts from the Second International Symposium on Clinical, Biochemical, and Molecular Aspects of Fatty Acid Oxidation Defects. Philadelphia, abstr P-10

16. Chinsky J, Tolsma T, Cowan T, Blitzer M 1991 MCAD deficiency in SIDS. Am J Hum Genet 49 (suppl): 183(abstr) 